\title{
Nasal salmon calcitonin blunts bone microstructure alterations in healthy postmenopausal women
}

\author{
R. Rizzoli • A. Sigaud • M. Azria • F. R. Herrmann
}

Received: 11 January 2014 / Accepted: 8 October 2014 / Published online: 22 October 2014

(C) International Osteoporosis Foundation and National Osteoporosis Foundation 2014

\begin{abstract}
Summary In healthy postmenopausal women, nasal salmon calcitonin blunted distal radius and tibia bone microstructure degradation.

Introduction Nasal salmon calcitonin (NSC) has been reported to lower vertebral fracture risk by $33 \%$, but to modestly increase spine areal bone mineral density (aBMD) by $1.5 \%$. Thus, NSC may also influence bone microstructure, another known determinant of bone strength.

Methods In a randomized, double-blind, placebo-controlled trial, we investigated the effects of $200 \mathrm{IU} /$ day NSC on distal radius and tibia bone microstructure (by high-resolution 3dimensional peripheral quantitative computerized tomography), aBMD (by dual-energy X-ray absorptiometry), and serum bone turnover markers in healthy postmenopausal women.

Results Mean age was $57.6 \pm 0.8( \pm$ SEM) and $57.4 \pm 0.7$ in NSC $(n=45)$ and placebo groups $(n=45)$, respectively. Mean femoral neck T-score was in the osteopenic range; prevalent vertebral fracture was $4 \%$ in each group. There was no observed between-group difference in the primary outcome distal radius BV/TV ( $-2.8 \pm 0.6 \%$ vs. $-4.3 \pm 1.0 \%$, NS). By 2 years, the decrease in distal radius total density vs. baseline was $4.4 \pm 0.7 \%$ in controls and $2.1 \pm 0.6 \%$ in NSC-receiving patients $(p<0.05)$. Distal radius and tibia cortical thickness decreased by $3.7 \pm 1.0$ and $2.4 \pm 0.5 \%$ in placebo ( $p<0.05$ vs. baseline for both), respectively, but not in the NSC group. Distal radius total density and cortical thickness changes were lower in NSC group than in placebo ( $p<0.05$ for both) in the
\end{abstract}

R. Rizzoli $(\bowtie) \cdot$ A. Sigaud $\cdot$ F. R. Herrmann

Division of Bone Diseases, Department of Internal Medicine

Specialties, Geneva University Hospitals and Faculty of Medicine,

1211 Geneva 14, Switzerland

e-mail: rene.rizzoli@unige.ch

M. Azria

4054 Basel, Switzerland subgroup with baseline C-terminal telopeptides (CTX) above the median. By 6 and 12 months, serum CTX decreased by $17.3 \pm 6.2$ and $19.1 \pm 6.6 \%$ (both $p<0.05$ vs. baseline), respectively, in NSC, but remained stable in controls (NS vs. baseline). There was no difference in aBMD. NSC was well tolerated, with less arthralgia than the placebo group (14 vs. $26, p<0.05)$.

Conclusion Nasal salmon calcitonin blunted the degradation of distal radius and tibia bone microstructure in healthy postmenopausal women.

Keywords Bone resorption · Fracture · Osteoporosis · Prevention $\cdot$ Treatment

\section{Introduction}

Osteoporosis is characterized by low bone mass and compromised bone strength, leading to an increased risk of fracture [1]. Bone strength is explained by several bone characteristics including bone mass, geometry, microstructure, remodeling, and material level properties [2]. Bone mineral mass is currently evaluated by areal bone mineral density (aBMD) using dual-energy X-ray absorptiometry (DXA). At least $60 \%$ of the variance of the compression or flexion strength is explained by aBMD [2]. Microstructure comprises trabecular number, thickness and separation, cross-sectional area (CSA), cortical thickness, and porosity [3, 4].

High-resolution 3-dimensional peripheral quantitative computerized tomography (HR-pQCT) allows for the quantitative evaluation of volumetric bone density and bone microstructure at the distal radius and distal tibia [3].

Several antiresorptive pharmacological agents are available. While all of these agents positively impact on bone strength, their known mechanisms of action and efficacies differ [5-7]. The antiresorptive, calcitonin, is an inhibitor of 
osteoclast activity $[8,9]$. Its parenteral administration, via injections of 100 IU every 1 or 2 days, can prevent postmenopausal or post-ovariectomy bone loss. Calcitonin has also been shown to preserve trabecular bone mass among patients with established osteoporosis [9, 10]. Prolonged treatment with calcitonin injections, however, is difficult to maintain over the long term. A better tolerated formula of calcitonin is one that is administered via the nasal passage, with side effects being rare. Administration of $200 \mathrm{IU}$ of nasal calcitonin (NSC) inhibits bone resorption and increases lumbar spine BMD by $1.7-3.3 \%$ after 1 year [11-14]. In one trial, this dose of NSC was reported to lower vertebral fracture risk by $33 \%$, with only a $1.5 \%$ increase in spine aBMD [15]. In addition, NSC may also influence microstructure, another important determinant of bone strength, which is not captured in aBMD measurements. Indeed, NSC has been shown to attenuate microstructural degradation in specific regions of the distal radius and of the lower trochanter using magnetic resonance imaging in osteoporotic postmenopausal women [15]. However, treatment of postmenopausal osteoporosis with calcitonin may be limited due to a possible escape phenomenon.

In the present study, we investigated the effects of NSC on the microstructure of peripheral, weight-bearing, and non weight-bearing bones in non-osteoporotic, healthy postmenopausal women using HR-pQCT.

Treatment of rodents with calcitonin leads to the stimulation of sclerostin, a protein secreted by osteocytes embedded within the cortical bone that is known to inhibit osteoblast formation [16]. Increases in sclerostin may affect the balance between bone formation and bone resorption following calcitonin treatment, but data from human studies does not exist. Thus, we also measured changes in sclerostin levels in response to NSC administration in humans in the current study.

\section{Subjects and methods}

This single-center, double-blind, randomized, placebocontrolled, 2-year trial assessed the effects of NSC (200 IU/day) on bone microstructure in non-osteoporotic postmenopausal women [17] (registered number: ClinTrial. Gov: NCT00372099). The protocol was approved by the Geneva University Hospitals ethics committee. All subjects signed a written informed consent prior to commencement.

\section{Study population}

The study population consisted of 90 postmenopausal women aged 45 to 70 years with a T-score of between 0.0 and -2.49 (spine, total hip, or femoral neck as measured by DXA). The inclusion criteria were women with natural or surgical menopause for $\geq 1$ year.

Exclusion criteria were osteoporosis (T-score $\leq-2.5$ at spine, total hip, or femoral neck); severe vertebral fracture(s) as identified by DXA-based vertebral fracture assessment at baseline; any history of metabolic disease that might affect bone metabolism such as primary hyperparathyroidism, osteogenesis imperfecta, Paget's disease, osteomalacia, and thyroid disease (if receiving thyroid hormone replacement, the patients had to be euthyroid and on a stable dose of thyroid hormone); impaired renal function (estimated GFR $<30 \mathrm{ml} / \mathrm{min}$ ); history of previous or active malignancy of any organ system, treated or not within the past 5 years; history of corticosteroid treatments for 6 months or more at daily dosage $\geq 5 \mathrm{mg}$ of prednisone equivalent; BMI $\leq 18$ or $\geq 30 \mathrm{~kg} / \mathrm{m}^{2}$; and any treatment with estrogens, SERMs, tibolone, calcitonin, strontium ranelate, teriparatide or $\mathrm{PTH}$, oral bisphosphonates in the previous year, with a duration $\geq 2$ weeks, or any prior intravenous bisphosphonate.

\section{Trial design}

Patients who fulfilled all the inclusion/exclusion criteria were randomized 1:1 to treatment (200 IU salmon calcitonin nasal spray, once daily) or matching placebo nasal spray, using a computer-generated randomization list. All patients also received oral doses of $880 \mathrm{IU} /$ day of vitamin D and 1,000 mg/day of calcium. Patients, investigative staff, technicians performing the assessments, and data analysts remained blinded to the identity of the treatment from the time of randomization until the database lock. Study medication used, dosages administered, and intervals between visits were recorded. Drug accountability was recorded at each visit, which took place at 6-month intervals, and at the completion of the trial at 24 months. Patients were asked to return all unused medication at each visit.

The primary efficacy endpoint was the effect of calcitonin on distal radius relative bone volume (BV/TV) as evaluated by HR-pQCT in healthy postmenopausal women compared to placebo over 2 years.

\section{Safety assessment}

Safety assessments consisted of monitoring and recording all adverse events, including serious adverse events, whether spontaneously reported by the subject, discovered by investigator questioning, or detected by physical examination or laboratory test outcome. 


\section{Bone measurements}

Spine and hip aBMD was measured at baseline, at 12 months, and at the final visit ( 24 months) by DXA (Lunar Prodigy GE Healthcare, Madison, WI). At baseline, an evaluation of vertebral body deformity using the Vertebral Fracture Assessment program followed by an analysis using Genant's grading was performed [18].

Distal radius and distal tibia volumetric BMD and microstructure were determined using a XtremCT HRpQCT instrument (Scanco Medical, Bassersdorf, Switzerland) also at baseline, at 12 months, and at the final visit (24 months). Measurements (110 slices) were performed proximally, at a given distance to a specific location according to the manufacturer's recommendations. The variables measured were Dtot (total density), Dtrab (trabecular bone density), Dcort (cortical bone density), $\mathrm{BV} / \mathrm{TV}$ (trabecular bone volume to tissue volume), Tb.N (number of trabeculae), Tb.Th (trabecular thickness), Tb. Sp (trabecular separation), Tb.1/N.SD (heterogeneity of trabecular network), C.Th (cortical thickness), cortical perimeter, cortical porosity [19], cortical pore diameter, and polar moment of inertia-a calculated estimate of resistance to torsion. The in vivo shortterm reproducibility of HR-pQCT measurements was 0.7 to $1.0 \%$ for volumetric BMD and 3.0 to $4.9 \%$ for trabecular and cortical microstructure [4]. Due of the risk of limb motion during data acquisition, which precludes reliable analysis, some differences in the number of interpretable data may exist.

The effective dose for one XtremCt standard measurement is $3 \mu \mathrm{Sv}$ per site. Thus, for three determinations at two sites, this represented $18 \mu \mathrm{Sv}$. With $6 \mu \mathrm{Sv}$ per DXA examination (three for the spine and three for the hip), the total irradiation was around $36 \mu \mathrm{Sv}$ over the whole study.

\section{Laboratory}

All blood and second morning urination samples were collected after an overnight fast. Bone turnover markers (procollagen type I N-terminal propeptide, PINP, and Cterminal telopeptides, CTX), PTH, and 25-OH-vitamin $\mathrm{D}$ (both vitamin $\mathrm{D}_{3}$ and $\mathrm{D}_{2}$ ) were measured batchwise on a Cobas-6000 instrument using Elecsys reagents (Roche Diagnostic, Rotkreuz, Switzerland). Sclerostin was determined using the TECO two-site immune capture ELISA (Teco Medical, Sissach, Switzerland), with one antibody that recognizes the amino-terminus of the molecule and one the mid-region [20]. Human recombinant sclerostin was used as standard. Serum calcitonin analyses were carried out in the laboratory of Dr Moise Azria at Novartis (Basel, Switzerland). Determinations of calcium, phosphate, albumin, creatinine, and bonespecific alkaline phosphatase were performed using routine methods. Renal tubular reabsorption of calcium and phosphate was estimated using previously published algorithms [21].

\section{Statistical analysis}

A total of 80 patients (40 in calcitonin group and 40 in control group) were necessary in order to have a statistical power of $80 \%$, with an expected difference of $3.5 \%$ in $\mathrm{BV} / \mathrm{TV}$. Values are expressed as means $\pm \mathrm{SEM}$. Paired and unpaired two-side Student's $t$ tests were applied for comparison of all variables, except a chisquare test for proportions. In addition, in a post hoc subgroup analysis, a two-way ANOVA with interaction evaluation was applied. All analyses were on a per protocol basis. Indeed, the patients who decided to stop treatment declined to come back for a final consultation.

\section{Results}

Between January 2007 and October 2009, 90 out of 121 assessed postmenopausal women fulfilled the inclusion/ exclusion criteria and were randomized to $200 \mathrm{IU} /$ day NSC or placebo. All received in additional $1,000 \mathrm{mg} /$ day of calcium element and 880 IU/day of vitamin D3. During the first year of the trial, five and four in the placebo and treatment groups, respectively, dropped out (Fig. 1), and one and eight during the second year. The reasons for withdrawal were discovery of a tonsil carcinoma (one), adverse events (three), introduction of hormone replacement therapy (one), and voluntary withdrawal (one) in the placebo group, and the discovery of a breast cancer (one), adverse events (five), hormone replacement therapy (two), diagnosis of osteoporosis (one), and bad compliance or lack of follow-up (three) in the NSC-treated group.

\section{Baseline values}

Baseline characteristics across both groups were not different (Table 1). Prevalent fractures (zero in NSC group vs. three in placebo) were not statistically different. Twenty-nine percent of patients in each group had serum 25-hydroxy-vitamin D values above $75 \mathrm{nmol} / \mathrm{l}$, and 69 and $64 \%$ above $50 \mathrm{nmol} / 1$ in the placebo and treated groups, respectively. Only 7 and $9 \%$ were in the deficiency range [22]. Bone turnover marker values were within the expected range for postmenopausal women and similar in both groups, as were 
Fig. 1 Flow chart of the trial

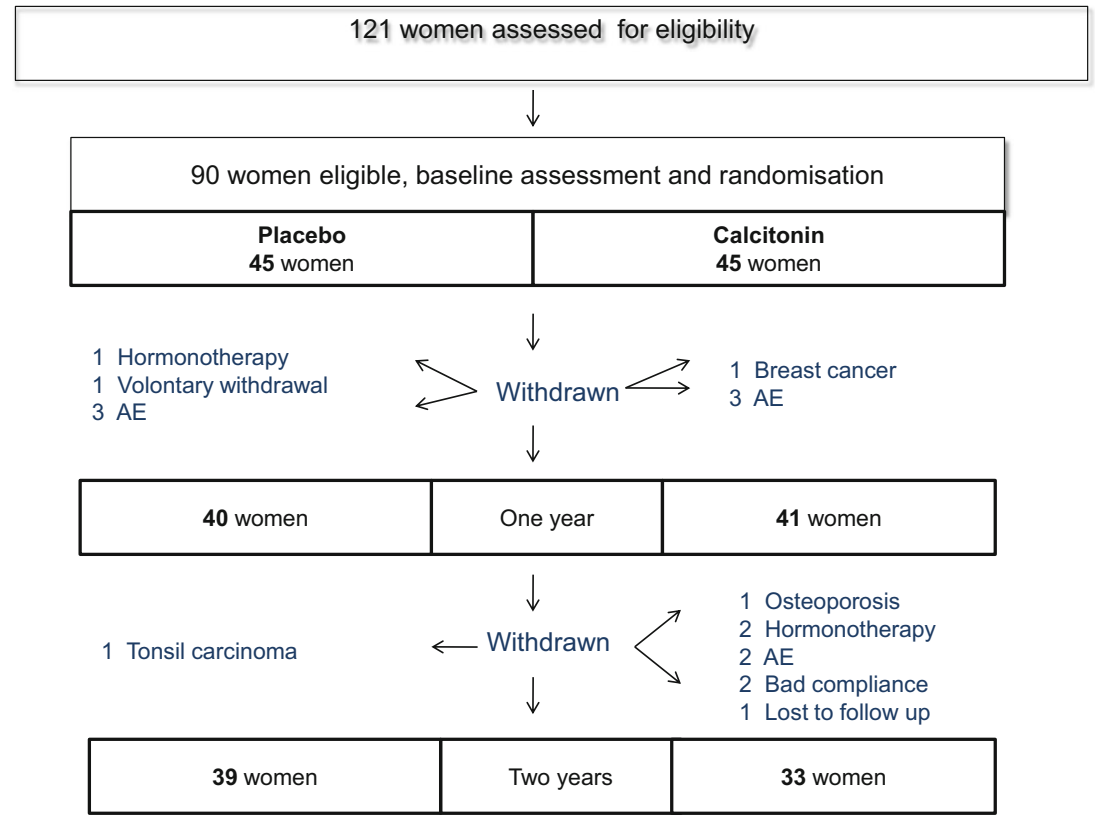

PTH and the renal tubular reabsorption rates of calcium and phosphate. Baseline sclerostin levels were slightly lower in the NSC-treated group at baseline $(p<0.05)$. Areal and volumetric BMD as well as most of the microstructure values did not differ between the two groups (Table 2), except a lower distal radius cortical pore diameter in the NSC-treated group. The prevalence of osteopenia was 67 and $71 \%$ in placebo and NSC-treated groups, respectively.

\section{Effects of nasal salmon calcitonin}

At the 2-year time point, distal radius $\mathrm{BV} / \mathrm{TV}$ had decreased by $4.3 \pm 1.0 \%$ in the placebo and the $2.8 \pm$ $0.6 \%$ in NSC group compared to baseline but these decreases were not different, indicating no betweengroup difference in the primary endpoint (Table 3 and Fig. 2). In contrast, the decrease in distal radius total density of $4.4 \pm 0.7 \%$ in the placebo was statistically less in the NSC group $(2.1 \pm 0.6 \%)(p<0.05)$. The increase in radius trabecular area was less in NSCreceiving patients than in placebo $(p<0.05)$. By 2 years, a series of variables decreased ( $p<0.05$ vs. baseline) in the placebo, but not in the NSC group (Table 3, Fig. 2), including: distal radius cortical thickness and perimeter, and distal tibia trabecular number and cortical thickness. Similarly, distal tibia trabecular separation and heterogeneity increased in placebo ( $p<0.05$ vs. baseline), but not in the NSC group. By 1 year, distal tibia measurements showed that total and trabecular density, BV/TV, and cortical thickness and area all decreased in the placebo group ( $p<0.05$ vs. baseline), but not in NSCreceiving patients.

There were no between-group differences in aBMD at any site (Table 3). Femoral neck aBMD similarly decreased over time in both the placebo and NSC groups.

Under NSC, serum CTX decreased by 17.3 and $19.5 \%$ by 6 and 12 months after commencing therapy, whereas it did not change in the placebo group, with a significant between group difference at 6 months (Table 4 ). P1NP remained stable in both groups, with a small decrease by 18 months in the placebo, but not in the NSC group. Bone-specific alkaline phosphatase similarly decreased over time in the placebo and NSC groups. In relation to vitamin D supplementation, there was a 74 and $65 \%$ increase in 25-hydroxy vitamin D levels in placebo and treated groups, respectively. From 18 months on, sclerostin decreased in the placebo, but not in the NSC group. PTH levels remained constant, except for an increase detected in the NSC group by 24 months.

It has been suggested that the response to calcitonin may depend on the level of bone remodeling [23]. We re-analyzed, post hoc, the HR-pQCT results in subgroups defined by the median of baseline CTX values. In patients with baseline CTX above the median, distal radius total density, cortical density and area, and polar moment of inertia decreased less in the NSC group as compared with the placebo by 2 years, using a $t$ test (between group difference $p<0.05$; Table 5, Fig. 3). Distal tibia trabecular area increased significantly less in NSC than in the placebo group. Using a two-factor ANOVA on data obtained at this time point, only a 
Table 1 Baseline subjects' and biochemical characteristics

\begin{tabular}{|c|c|c|}
\hline & $\begin{array}{l}\text { Placebo } \\
N=45\end{array}$ & $\begin{array}{l}\text { Calcitonin } \\
N=45\end{array}$ \\
\hline Age (years) & $57.4 \pm 0.7$ & $57.6 \pm 0.8$ \\
\hline Height $(\mathrm{cm})$ & $163.9 \pm 0.8$ & $162.2 \pm 0.7$ \\
\hline Weight (kg) & $64.9 \pm 1.2$ & $62.2 \pm 1.2$ \\
\hline BMI $\left(\mathrm{kg} / \mathrm{m}^{2}\right)$ & $24.1 \pm 0.4$ & $23.6 \pm 0.4$ \\
\hline Years since menopause (years) & $6.8 \pm 0.6$ & $8.2 \pm 0.9$ \\
\hline Surgical menopause & $2 \%$ & $4 \%$ \\
\hline Family history of fracture & $16 \%$ & $29 \%$ \\
\hline Smokers & $38 \%$ & $31 \%$ \\
\hline Previous & $24 \%$ & $22 \%$ \\
\hline Current & $13 \%$ & $9 \%$ \\
\hline Prevalent fracture $>45$ years & $7 \%$ & $0 \%$ \\
\hline \multicolumn{3}{|l|}{ Vertebral fracture assessment } \\
\hline$\%$ with fracture & $4 \%$ & $4 \%$ \\
\hline \% with fracture grade II or III & $4 \%$ & $4 \%$ \\
\hline History of bone influencing drugs $(\%)^{\mathrm{a}}$ & $51 \%$ & $47 \%$ \\
\hline Calcium corrected for albumin (mmol/l) & $2.30 \pm 0.01$ & $2.28 \pm 0.01$ \\
\hline Phosphate $(\mathrm{mmol} / \mathrm{l})$ & $1.19 \pm 0.02$ & $1.19 \pm 0.02$ \\
\hline Creatinine $(\mu \mathrm{mol} / 1)$ & $74.0 \pm 2.8$ & $70.0 \pm 1.9$ \\
\hline Albumin (g/l) & $39.0 \pm 0.3$ & $39.0 \pm 0.4$ \\
\hline $25-\mathrm{OH}$ vit $\mathrm{D}(\mathrm{nmol} / \mathrm{l})$ & $62.9 \pm 4.4$ & $61.7 \pm 4.6$ \\
\hline$<25 \mathrm{nmol} / 1$ & $7 \%$ & $9 \%$ \\
\hline$<50 \mathrm{nmol} / 1$ & $31 \%$ & $36 \%$ \\
\hline$<75 \mathrm{nmol} / 1$ & $71 \%$ & $71 \%$ \\
\hline PTH (pmol/1) & $4.0 \pm 0.2$ & $3.8 \pm 0.2$ \\
\hline Bone-specific alkaline phosphatase $(\mu \mathrm{g} / \mathrm{l})$ & $12.9 \pm 0.5$ & $11.9 \pm 0.5$ \\
\hline CTX-1 (ng/l) & $538.4 \pm 33.2$ & $493.4 \pm 24.5$ \\
\hline P1NP $(\mu g / 1)$ & $55.86 \pm 2.89$ & $52.47 \pm 2.41$ \\
\hline Sclerostin (ng/ml) & $0.90 \pm 0.04$ & $0.80 \pm 0.03 *$ \\
\hline TRCaI (mmol/l GFR) & $2.60 \pm 0.02$ & $2.59 \pm 0.02$ \\
\hline TmPi/GFR (mmol/l GFR) & $1.19 \pm 0.03$ & $1.20 \pm 0.02$ \\
\hline
\end{tabular}

The values are means \pm SEM

TRCaI tubular reabsorption of calcium index, TmPi/GFR tubular reabsoption of phosphate

$* p<0.05$ between groups

${ }^{a}$ For more than 3 months and less than 12 months; hormone replacement therapy or SERMs (selective estrogen receptor modulators): 29 vs $36 \%$, calcium-vitamin D supplements: 11 vs $9 \%$, glucocorticoids: 4 vs $2 \%$, bisphosphonates/calcitonin: 2 vs $2 \%$, in calcitonin vs placebo groups, respectively

trend $(p<0.1)$ for differences in distal radius trabecular separation and heterogeneity, and distal tibia trabecular thickness and number was found. These data support a mild effect of NSC on bone microstructure, particularly in subjects with higher bone turnover.

Over the 2-year treatment period, a decrease in standing height in the placebo group was observed $(-0.4 \pm 0.1 \mathrm{~cm}$, $p<0.05)$, which was not detectable in the NSC group $(+0.1 \pm$ $0.1 \mathrm{~cm}, \mathrm{NS})$. Two peripheral fractures occurred in the placebo, and one in the NSC group.

\section{Adverse events}

The incidence of adverse events was equally distributed among the placebo and the NSC-treated groups. However, there was a lower occurrence of arthralgia complaints in the calcitonin group compared to placebo (14 $(31 \%)$ vs. $26(58 \%), p<0.02)$. Anti-calcitonin antibodies were detected in 18 NSC-treated subjects by 24 months $(272.3 \pm 42.3 \mathrm{ng} / \mathrm{ml})$. The presence or absence of these antibodies had no effect on the CTX levels (data not shown).

\section{Discussion}

Following its discovery in 1962 by H. Copp [24], an injectable form of calcitonin came on the market in Europe in 1973 and a nasal spray in 1987. More recently, an oral form has been shown to be superior to the nasal spray in increasing BMD and possibly in reducing bone turnover in women with postmenopausal osteoporosis [25]. Nasal salmon calcitonin has been used in the treatment of postmenopausal osteoporosis, with some anti-vertebral fracture efficacy reported in one study, without commensurate changes in aBMD [12]. We undertook the present trial to address the issue of volumetric BMD and microstructure changes in response to NSC. This single-center, double-blind, placebo-controlled, randomized trial assessed the effects of NSC in healthy postmenopausal women without osteoporosis. It is the first study on bone microstructure in response to NSC in non-osteoporotic healthy women, using HR-pQCT.

There were no between-group differences in the primary endpoint, distal radius $\mathrm{BV} / \mathrm{TV}$, or in areal spine or proximal femur BMD. Though not statistically significant, the smaller decrease in distal radius $\mathrm{BV} / \mathrm{TV}$ in the NSC group, $2.8 \%$, versus the $4.3 \%$ observed in placebo patients by 2 years was comparable to the findings of the QUEST study [15]. In the latter trial, the effects of NSC were detected at specific sites of the forearm using MRI. Thus, bone site specificity, differences in the age of participants (average $57 \mathrm{vs}$. 67 years), differences in the number of years post menopause (7 vs. 19), and the degree of calcium supplementation (500 vs. $1,000 \mathrm{mg} /$ day) may contribute to some of the discrepancies observed between the two studies. The lack of effects of NSC on aBMD is in full 
Table 2 Baseline areal BMD, volumetric $\mathrm{BMD}$ and bone microstructure characteristics
The values are means \pm SEM ${ }^{*} p<0.05$ between groups using a $t$ test

\begin{tabular}{|c|c|c|c|}
\hline & & Placebo $N=43$ & Calcitonin $N=42$ \\
\hline \multirow[t]{2}{*}{ Lumbar spine } & $\operatorname{BMD}\left(\mathrm{g} / \mathrm{cm}^{2}\right)$ & $1.055 \pm 0.020$ & $1.070 \pm 0.017$ \\
\hline & T-score & $-1.02 \pm 0.16$ & $-0.88 \pm 0.14$ \\
\hline \multirow[t]{2}{*}{ Total hip } & $\operatorname{BMD}\left(\mathrm{g} / \mathrm{cm}^{2}\right)$ & $0.936 \pm 0.020$ & $0.913 \pm 0.012$ \\
\hline & T-score & $-0.58 \pm 0.13$ & $-0.77 \pm 0.10$ \\
\hline \multirow[t]{2}{*}{ Femoral neck } & $\operatorname{BMD}\left(\mathrm{g} / \mathrm{cm}^{2}\right)$ & $0.898 \pm 0.010$ & $0.867 \pm 0.009$ \\
\hline & T-score & $-1.01 \pm 0.10$ & $-1.23 \pm 0.07$ \\
\hline \multicolumn{4}{|l|}{ Radius } \\
\hline \multicolumn{2}{|c|}{ Total density (mg HA/cm³) } & $325.20 \pm 9.70$ & $311.90 \pm 10.30$ \\
\hline \multicolumn{2}{|c|}{ Trabecular density (mg HA/ $/ \mathrm{cm}^{3}$ ) } & $148.00 \pm 6.10$ & $149.40 \pm 5.00$ \\
\hline \multicolumn{2}{|c|}{$\mathrm{BV} / \mathrm{TV}(1)$} & $0.12 \pm 0.01$ & $0.13 \pm 0.00$ \\
\hline \multicolumn{2}{|c|}{ Trabecular number $(1 / \mathrm{mm})$} & $1.77 \pm 0.06$ & $1.88 \pm 0.04$ \\
\hline \multicolumn{2}{|c|}{ Trabecular thickness (mm) } & $0.07 \pm 0.00$ & $0.07 \pm 0.00$ \\
\hline \multicolumn{2}{|c|}{ Trabecular separation (mm) } & $0.53 \pm 0.03$ & $0.48 \pm 0.01$ \\
\hline \multicolumn{2}{|c|}{ Tb.1/N.SD (mm) } & $0.28 \pm 0.03$ & $0.23 \pm 0.02$ \\
\hline \multicolumn{2}{|c|}{ Trabecular area $\left(\mathrm{mm}^{2}\right)$} & $198.50 \pm 7.10$ & $203.70 \pm 7.00$ \\
\hline \multicolumn{2}{|c|}{ Cortical density $\left(\mathrm{mg} \mathrm{HA} / \mathrm{cm}^{3}\right)$} & $900.00 \pm 9.80$ & $886.40 \pm 7.60$ \\
\hline \multicolumn{2}{|c|}{ Cortical thickness (mm) } & $0.79 \pm 0.03$ & $0.74 \pm 0.03$ \\
\hline \multicolumn{2}{|c|}{ Cortical area $(\mathrm{mm})$} & $53.10 \pm 1.60$ & $49.40 \pm 1.30$ \\
\hline \multicolumn{2}{|c|}{ Cortical perimeter (mm) } & $67.90 \pm 0.90$ & $67.70 \pm 0.90$ \\
\hline \multicolumn{2}{|c|}{ Cortical porosity $(\%)$} & $2.23 \pm 0.20$ & $1.90 \pm 0.10$ \\
\hline \multicolumn{2}{|c|}{ Cortical pore diameter (mm) } & $0.181 \pm 0.004$ & $0.168 \pm 0.004^{*}$ \\
\hline \multirow{2}{*}{\multicolumn{2}{|c|}{ Polar moment of inertia $\left(\mathrm{mm}^{\wedge} 4\right)$}} & $3,931.7 \pm 126.5$ & $3,738.7 \pm 108.2$ \\
\hline & & Placebo $N=45$ & Calcitonin $N=45$ \\
\hline \multicolumn{4}{|l|}{ Tibia } \\
\hline \multicolumn{2}{|c|}{ Total density $\left(\mathrm{mg} \mathrm{HA} / \mathrm{cm}^{3}\right)$} & $272.60 \pm 7.20$ & $265.90 \pm 7.10$ \\
\hline \multicolumn{2}{|c|}{ Trabecular density $\left(\mathrm{mg} \mathrm{HA} / \mathrm{cm}^{3}\right)$} & $156.10 \pm 5.60$ & $152.30 \pm 5.00$ \\
\hline \multicolumn{2}{|c|}{$\mathrm{BV} / \mathrm{TV}(1)$} & $0.13 \pm 0.01$ & $0.13 \pm 0.00$ \\
\hline \multicolumn{2}{|c|}{ Trabecular number $(1 / \mathrm{mm})$} & $1.71 \pm 0.04$ & $1.80 \pm 0.04$ \\
\hline \multicolumn{2}{|c|}{ Trabecular thickness (mm) } & $0.08 \pm 0.00$ & $0.07 \pm 0.00$ \\
\hline \multicolumn{2}{|c|}{ Trabecular separation (mm) } & $0.53 \pm 0.02$ & $0.50 \pm 0.01$ \\
\hline \multicolumn{2}{|c|}{ Tb.1/N.SD $(\mathrm{mm})$} & $0.25 \pm 0.01$ & $0.23 \pm 0.01$ \\
\hline Trabecular a & & $586.40 \pm 16.70$ & $570.00 \pm 14.00$ \\
\hline Cortical dens & & $860.20 \pm 9.20$ & $849.10 \pm 7.70$ \\
\hline Cortical thicl & & $1.01 \pm 0.03$ & $0.99 \pm 0.03$ \\
\hline Cortical area & & $103.70 \pm 2.80$ & $99.90 \pm 2.60$ \\
\hline Cortical peri & & $103.50 \pm 1.20$ & $102.20 \pm 0.90$ \\
\hline Cortical porc & & $6.80 \pm 0.40$ & $7.26 \pm 0.49$ \\
\hline Cortical pore & & $0.203 \pm 0.004$ & $0.199 \pm 0.004$ \\
\hline Polar momer & $\left.m^{\wedge} 4\right)$ & $19,197.4 \pm 541.6$ & $18,366.6 \pm 410.1$ \\
\hline
\end{tabular}

agreement with a recently published study comparing oral to nasal calcitonin [25]. In contrast, the decrease in distal radius total density was significantly blunted in NSC-treated group by 2 years, as was the increase in trabecular area at the site. Furthermore, decreases in the distal radius and distal tibia cortical thickness in the placebo group was not detected in patients on NSC. This supports the hypothesis that NSC is able to blunt age- and menopause-related alterations in bone microstructure.

In agreement with the observation that calcitonin may be more efficacious in patients with high bone 
Table 3 Effect of nasal salmon calcitonin on aBMD, volumetric BMD, and microstructure

\begin{tabular}{|c|c|c|c|c|c|}
\hline & & \multicolumn{2}{|l|}{1 year } & \multicolumn{2}{|l|}{2 years } \\
\hline & & Placebo & Calcitonin & Placebo & Calcitonin \\
\hline \multicolumn{2}{|l|}{ Number of subjects } & 39 & 38 & 42 & 41 \\
\hline Lumbar spine & BMD (\%) & $-0.2 \pm 0.4$ & $0.4 \pm 0.6$ & $-0.7 \pm 0.5$ & $-0.7 \pm 0.7$ \\
\hline Total hip & BMD $(\%)$ & $0.2 \pm 0.3$ & $0.2 \pm 0.3$ & $-0.2 \pm 0.3$ & $-0.5 \pm 0.4$ \\
\hline Femoral neck & BMD (\%) & $-1.0 \pm 0.4 \#$ & $-1.4 \pm 0.5 \#$ & $-2.4 \pm 0.5 \#$ & $-2.1 \pm 0.5 \#$ \\
\hline \multicolumn{6}{|l|}{ Radius } \\
\hline \multicolumn{2}{|l|}{ Total density (\%) } & $-2.6 \pm 0.4 \#$ & $-1.9 \pm 0.5 \#$ & $-4.4 \pm 0.7 \#$ & $-2.1 \pm 0.5 * \#$ \\
\hline \multicolumn{2}{|l|}{ Trabecular density (\%) } & $-2.7 \pm 0.7 \#$ & $-2.1 \pm 0.4 \#$ & $-4.3 \pm 1.0 \#$ & $-2.8 \pm 0.6 \#$ \\
\hline \multicolumn{2}{|l|}{$\mathrm{BV} / \mathrm{TV}(\%)$} & $-2.7 \pm 0.7 \#$ & $-2.1 \pm 0.5 \#$ & $-4.3 \pm 1.0 \#$ & $-2.8 \pm 0.6 \#$ \\
\hline \multicolumn{2}{|l|}{ Trabecular number (\%) } & $-0.5 \pm 1.7$ & $-1.5 \pm 1.2$ & $-1.7 \pm 1.8$ & $-2.1 \pm 1.1$ \\
\hline \multicolumn{2}{|l|}{ Trabecular thickness (\%) } & $-2.1 \pm 1.3$ & $-0.4 \pm 1.1$ & $-1.6 \pm 1.6$ & $-0.4 \pm 1.2$ \\
\hline \multicolumn{2}{|l|}{ Trabecular separation (\%) } & $1.9 \pm 1.8$ & $2.2 \pm 1.2$ & $4.3 \pm 2.9$ & $2.9 \pm 1.2 \#$ \\
\hline \multicolumn{2}{|l|}{ Tb.1/N.SD (\%) } & $4.6 \pm 3.5$ & $2.2 \pm 1.5$ & $13.5 \pm 9.0$ & $4.1 \pm 1.4 \#$ \\
\hline \multicolumn{2}{|l|}{ Trabecular area $(\%)$} & $0.5 \pm 0.2 \#$ & $0.3 \pm 0.1 \#$ & $1.0 \pm 0.2 \#$ & $0.3 \pm 0.2 *$ \\
\hline \multicolumn{2}{|l|}{ Cortical density (\%) } & $-1.3 \pm 0.3 \#$ & $-1.0 \pm 0.3 \#$ & $-2.0 \pm 0.4 \#$ & $-1.0 \pm 0.3 \#$ \\
\hline \multicolumn{2}{|l|}{ Cortical thickness (\%) } & $-2.0 \pm 0.7 \#$ & $1.8 \pm 0.6 \#$ & $-3.7 \pm 1.0 \#$ & $-2.6 \pm 1.4$ \\
\hline \multicolumn{2}{|l|}{ Cortical area $(\%)$} & $-2.0 \pm 0.6 \#$ & $-1.9 \pm 0.7 \#$ & $-3.9 \pm 1.0 \#$ & $-1.7 \pm 0.7 \#$ \\
\hline \multicolumn{2}{|l|}{ Cortical perimeter $(\%)$} & $-0.1 \pm 0.1$ & $0.0 \pm 0.1$ & $-0.2 \pm 0.1 \#$ & $1.9 \pm 2.1$ \\
\hline \multicolumn{2}{|l|}{ Cortical porosity (\%) } & $2.4 \pm 3.9$ & $6.3 \pm 5.3$ & $13.6 \pm 4.5 \#$ & $16.8 \pm 7.4 \#$ \\
\hline \multicolumn{2}{|l|}{ Cortical pore diameter $(\%)$} & $-0.3 \pm 1.8$ & $1.1 \pm 2.1$ & $1.8 \pm 1.9$ & $3.2 \pm 1.9$ \\
\hline \multicolumn{2}{|l|}{ Polar moment of inertia (\%) } & $-1.8 \pm 0.6 \#$ & $-2.2 \pm 0.6 \#$ & $-3.3 \pm 0.9 \#$ & $-1.4 \pm 0.6 \#$ \\
\hline \multicolumn{6}{|l|}{ Tibia } \\
\hline \multicolumn{2}{|l|}{ Total density (\%) } & $-1.9 \pm 0.5 \#$ & $-1.0 \pm 0.5$ & $-3.0 \pm 0.5 \#$ & $-1.7 \pm 0.6 \#$ \\
\hline \multicolumn{2}{|l|}{ Trabecular density $(\%)$} & $-1.8 \pm 0.6 \#$ & $-1.1 \pm 0.6$ & $-2.5 \pm 0.7 \#$ & $-1.4 \pm 0.6 \#$ \\
\hline \multicolumn{2}{|l|}{$\mathrm{BV} / \mathrm{TV}(\%)$} & $-1.7 \pm 0.6 \#$ & $-1.1 \pm 0.6$ & $-2.5 \pm 0.7 \#$ & $-1.4 \pm 0.6 \#$ \\
\hline \multicolumn{2}{|l|}{ Trabecular number (\%) } & $0.4 \pm 1.4$ & $-1.5 \pm 1.1$ & $-2.7 \pm 1.2 \#$ & $-0.2 \pm 1.4$ \\
\hline \multicolumn{2}{|l|}{ Trabecular thickness (\%) } & $-1.6 \pm 1.3$ & $0.9 \pm 1.0$ & $0.7 \pm 1.2$ & $-0.6 \pm 1.2$ \\
\hline \multicolumn{2}{|l|}{ Trabecular separation (\%) } & $0.8 \pm 1.5$ & $2.1 \pm 1.1$ & $3.9 \pm 1.3 \#$ & $1.2 \pm 1.4$ \\
\hline \multicolumn{2}{|l|}{ Tb.1/N.SD (\%) } & $1.1 \pm 1.5$ & $1.6 \pm 1.0$ & $3.3 \pm 1.2 \#$ & $0.9 \pm 1.5$ \\
\hline Trabecular area $(\%)$ & & $0.2 \pm 0.1 \#$ & $0.1 \pm 0.1$ & $0.4 \pm 0.1 \#$ & $0.2 \pm 0.1$ \\
\hline Cortical density (\%) & & $-1.4 \pm 0.3 \#$ & $-0.8 \pm 0.3 \#$ & $-2.1 \pm 0.3 \#$ & $-1.3 \pm 0.3 \#$ \\
\hline Cortical thickness (\%) & & $-1.1 \pm 0.4 \#$ & $-0.4 \pm 0.6$ & $-2.4 \pm 0.5 \#$ & $-1.2 \pm 0.6$ \\
\hline Cortical area $(\%)$ & & $-1.3 \pm 0.4 \#$ & $-0.6 \pm 0.6$ & $-2.6 \pm 0.5 \#$ & $-1.6 \pm 0.6 \#$ \\
\hline Cortical perimeter $(\%)$ & & $-0.2 \pm 0.1 \#$ & $-0.1 \pm 0.0 \#$ & $-0.2 \pm 0.1 \#$ & $-0.3 \pm 0.1 \#$ \\
\hline Cortical porosity (\%) & & $4.8 \pm 2.1 \#$ & $1.7 \pm 1.8$ & $8.7 \pm 2.3 \#$ & $8.6 \pm 3.2 \#$ \\
\hline Cortical pore diameter (\%) & & $0.8 \pm 1.4$ & $0.4 \pm 1.0$ & $2.6 \pm 1.2$ & $1.3 \pm 1.2$ \\
\hline Polar moment of inertia $(\%)$ & & $-1.2 \pm 0.6 \#$ & $-1.4 \pm 0.6 \#$ & $-2.9 \pm 0.6 \#$ & $-1.6 \pm 0.6 \#$ \\
\hline
\end{tabular}

The values are means \pm SEM and represent percent from baseline $\# p<0.05$ vs baseline; ${ }^{*} p<0.05$ between groups using a $t$ test

turnover [23], a post hoc analysis showed significant differences in distal radius total density and cortical thickness between NSC-treated and placebo receiving patients in the subgroup with baseline CTX levels above the median.
We observed a reduction in the bone turnover marker CTX, which primarily assesses bone resorption, of the same magnitude as was found in the PROOF trial [12]. Unlike the study comparing oral to nasal calcitonin [25], we did not detect any NSC-mediated change in 
Fig. 2 Time course of the effects of nasal salmon calcitonin (NSC) on distal radius and distal tibia total density, relative bone volume (BV/TV), and cortical thickness. Values are percent changes from baseline. Triangles and solid lines, placebo; circles and dashed lines, NSC. $\# p<0.05$ vs baseline. ${ }^{*} p<0.05$ betweengroup difference using a $t$ test

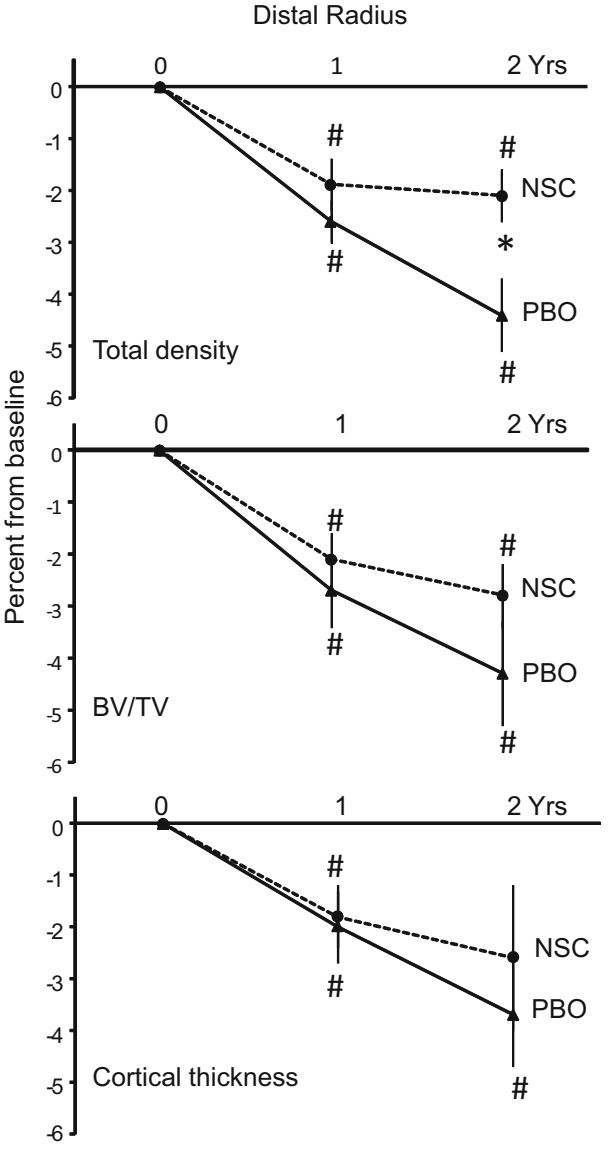

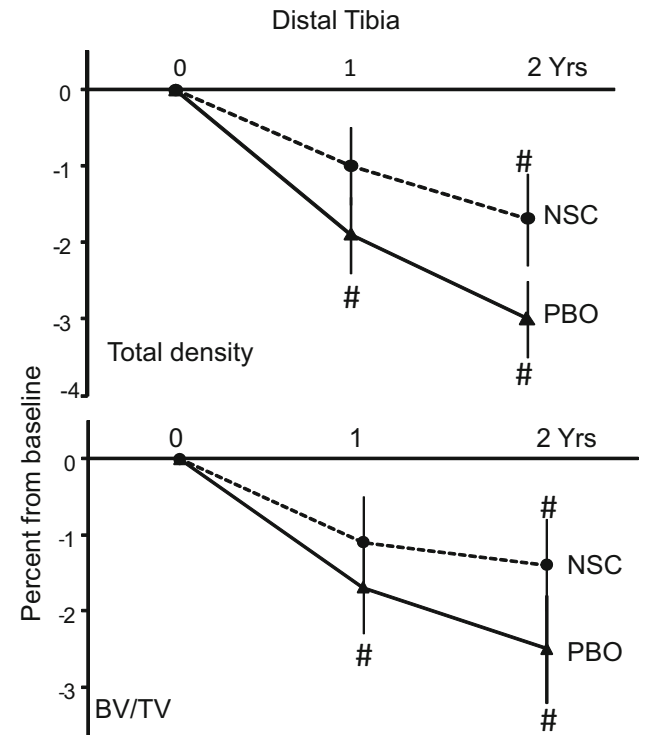

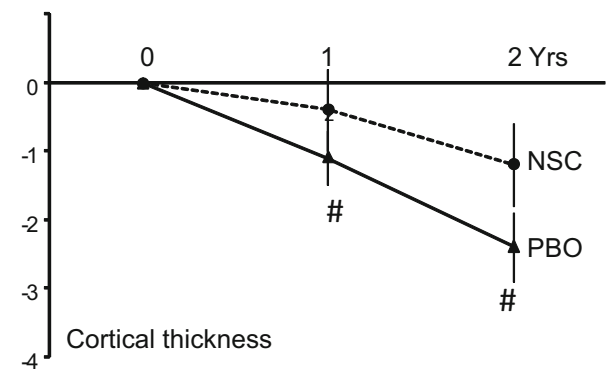

P1NP in our non-osteoporotic younger (57 vs. 66 years) healthy postmenopausal women. Deletion of the calcitonin and calcitonin gene-related peptide gene has been shown to be associated with an unexpected

Table 4 Effect of nasal calcitonin on biochemical variables

\begin{tabular}{|c|c|c|c|c|c|c|c|c|}
\hline \multirow[b]{2}{*}{ Number of subjects } & \multicolumn{2}{|l|}{6 months } & \multicolumn{2}{|l|}{1 year } & \multicolumn{2}{|l|}{18 months } & \multicolumn{2}{|l|}{2 years } \\
\hline & $\begin{array}{l}\text { Placebo } \\
43\end{array}$ & $\begin{array}{l}\text { Calcitonin } \\
42\end{array}$ & $\begin{array}{l}\text { Placebo } \\
40\end{array}$ & $\begin{array}{l}\text { Calcitonin } \\
38\end{array}$ & $\begin{array}{l}\text { Placebo } \\
40\end{array}$ & $\begin{array}{l}\text { Calcitonin } \\
35\end{array}$ & $\begin{array}{l}\text { Placebo } \\
43\end{array}$ & $\begin{array}{l}\text { Calcitonin } \\
42\end{array}$ \\
\hline $\begin{array}{l}\text { Calcium corrected for } \\
\text { albumin }(\%)\end{array}$ & & & $1.7 \pm 0.6$ & $1.8 \pm 0.7^{\#}$ & & & $0.9 \pm 0.6$ & $1.6 \pm 0.5^{\#}$ \\
\hline Creatinine $(\%)$ & & & $-2.4 \pm 2.0$ & $-3.3 \pm 2.3$ & & & $-1.7 \pm 2.0$ & $2.1 \pm 2.1$ \\
\hline $25-\mathrm{OH}$ vit D (\%) & & & $74.3 \pm 16.2^{\#}$ & $65.1 \pm 15.4^{\#}$ & & & $63.7 \pm 13.3^{\#}$ & $63 \pm 15.1^{\#}$ \\
\hline PTH $(\%)$ & & & $0.5 \pm 5.7$ & $9.1 \pm 7.5$ & & & $7.2 \pm 6.2$ & $31 \pm 11.1^{\#}$ \\
\hline CTX $1(\%)$ & $3.6 \pm 4.6$ & $-17.3 \pm 6.2^{\# *}$ & $-6.0 \pm 3.7$ & $-19.1 \pm 6.6^{\#}$ & $-6.0 \pm 5.6$ & $-19.5 \pm 5.9^{\#}$ & $-1.6 \pm 4.9$ & $1.0 \pm 5.1$ \\
\hline P1NP (\%) & $-7.1 \pm 4.7$ & $-7.9 \pm 4.9$ & $-11.5 \pm 3.1$ & $-6.9 \pm 5.6$ & $-11.0 \pm 4.7^{\#}$ & $-1.2 \pm 7.2$ & $-4.6 \pm 4.2$ & $-0.1 \pm 4.8$ \\
\hline BSAP (\%) & $-19.6 \pm 4.5^{\#}$ & $-16.7 \pm 3.6^{\#}$ & $-12.5 \pm 3.3^{\#}$ & $-10.6 \pm 3.4^{\#}$ & & & & \\
\hline Sclerostin $(\%)$ & $0.6 \pm 2.3$ & $0.5 \pm 2.3$ & $-1.8 \pm 2.7$ & $2.3 \pm 2.8$ & $-13.2 \pm 2.3^{\#}$ & $-5.7 \pm 2.9^{*}$ & $-10.4 \pm 3.5^{\#}$ & $-3.7 \pm 3.4$ \\
\hline TRCaI (\%) & & & $1.2 \pm 0.7$ & $0.9 \pm 0.7$ & & & $0.1 \pm 0.9$ & $2.7 \pm 0.7^{\# *}$ \\
\hline TmPi/GFR (\%) & & & $7.8 \pm 2.8^{\#}$ & $3.2 \pm 3.1$ & & & $3.2 \pm 2.7$ & $4 \pm 2.8$ \\
\hline
\end{tabular}

The values are given as the mean \pm SEM

$B S A P$ bone-specific alkaline phosphatase

$\# p<0.05$ vs baseline; ${ }^{*} p<0.05$ between groups using a $t$ test 
Table 5 Effect of nasal calcitonin on HR-pQCT results in relation to baseline CTX levels

\begin{tabular}{|c|c|c|c|c|c|c|c|c|}
\hline & \multicolumn{4}{|l|}{1 year } & \multicolumn{4}{|l|}{2 years } \\
\hline & \multicolumn{2}{|l|}{ Placebo } & \multicolumn{2}{|l|}{ Calcitonin } & \multicolumn{2}{|l|}{ Placebo } & \multicolumn{2}{|l|}{ Calcitonin } \\
\hline & $\begin{array}{l}<\mathrm{CTX} \\
\text { median }\end{array}$ & $\begin{array}{l}>\mathrm{CTX} \\
\text { median }\end{array}$ & $\begin{array}{l}<\mathrm{CTX} \\
\text { median }\end{array}$ & $\begin{array}{l}>\mathrm{CTX} \\
\text { median }\end{array}$ & $\begin{array}{l}<\mathrm{CTX} \\
\text { median }\end{array}$ & $\begin{array}{l}>\mathrm{CTX} \\
\text { median }\end{array}$ & $\begin{array}{l}<\mathrm{CTX} \\
\text { median }\end{array}$ & $\begin{array}{l}>\mathrm{CTX} \\
\text { median }\end{array}$ \\
\hline Number of subjects & 19 & 19 & 18 & 17 & 21 & 20 & 20 & 18 \\
\hline \multicolumn{9}{|l|}{ Radius } \\
\hline Total density (\%) & $-2.5 \pm 0.7^{\#}$ & $-2.8 \pm 0.5^{\#}$ & $-1.4 \pm 0.7^{\#}$ & $-2.5 \pm 0.6^{\#}$ & $-2.8 \pm 0.9^{\#}$ & $-6.1 \pm 0.9^{\#}$ & $-2.0 \pm 0.9^{\#}$ & $-2.2 \pm 0.6^{\# *}$ \\
\hline Trabecular density (\%) & $-2.6 \pm 1.1^{\#}$ & $-2.7 \pm 0.9^{\#}$ & $-1.9 \pm 0.6^{\#}$ & $-2.4 \pm 0.6^{\#}$ & $-3.1 \pm 1.4^{\#}$ & $-5.5 \pm 1.5^{\#}$ & $-2.7 \pm 1.0^{\#}$ & $-2.8 \pm 0.6^{\#}$ \\
\hline $\mathrm{BV} / \mathrm{TV}(\%)$ & $-2.6 \pm 1.1^{\#}$ & $-2.8 \pm 0.9^{\#}$ & $-1.8 \pm 0.7^{\#}$ & $-2.3 \pm 0.6^{\#}$ & $-3.1 \pm 1.4^{\#}$ & $-5.6 \pm 1.5^{\#}$ & $-2.7 \pm 1.0^{\#}$ & $-2.8 \pm 0.6^{\#}$ \\
\hline Trabecular number (\%) & $-0.2 \pm 2.1$ & $-0.9 \pm 2.7$ & $-1.1 \pm 1.6$ & $-1.9 \pm 1.7$ & $0.3 \pm 2.2$ & $-3.8 \pm 2.9$ & $-1.4 \pm 1.5$ & $-2.7 \pm 1.5$ \\
\hline Trabecular thickness (\%) & $0.3 \pm 2.2$ & $-2.3 \pm 2.3$ & $-0.3 \pm 1.7$ & $-0.5 \pm 1.4$ & $-2.9 \pm 1.5$ & $-0.3 \pm 2.9$ & $-0.9 \pm 1.6$ & $0.2 \pm 1.7$ \\
\hline $\begin{array}{l}\text { Trabecular separation } \\
(\%)\end{array}$ & $1.2 \pm 2.3$ & $2.6 \pm 2.8$ & $1.7 \pm 1.7$ & $2.7 \pm 1.7$ & $1.1 \pm 2.6$ & $7.7 \pm 5.3$ & $2.2 \pm 1.6$ & $3.6 \pm 1.7^{\#}$ \\
\hline Tb.1/N.SD (\%) & $-0.9 \pm 2.6$ & $10.1 \pm 6.3$ & $1.5 \pm 1.8$ & $3.0 \pm 2.3$ & $-0.3 \pm 2.9$ & $28.1 \pm 17.9$ & $2.1 \pm 1.7$ & $6.2 \pm 2.3^{\#}$ \\
\hline Trabecular area (\%) & $0.5 \pm 0.3$ & $0.5 \pm 0.2^{\#}$ & $0.0 \pm 0.2$ & $0.6 \pm 0.2^{\#}$ & $0.7 \pm 0.3^{\#}$ & $1.3 \pm 0.3^{\#}$ & $0.2 \pm 0.3$ & $0.4 \pm 0.2^{\# *}$ \\
\hline Cortical density (\%) & $-1.5 \pm 0.4^{\#}$ & $-1.1 \pm 0.4^{\#}$ & $-0.7 \pm 0.4^{\#}$ & $-1.2 \pm 0.4^{\#}$ & $-1.3 \pm 0.4^{\#}$ & $-2.7 \pm 0.5^{\#}$ & $-1.0 \pm 0.5^{\#}$ & $-1.0 \pm 0.4^{\# *}$ \\
\hline Cortical thickness (\%) & $-1.5 \pm 1.1$ & $-2.4 \pm 0.8^{\#}$ & $-1.1 \pm 0.9$ & $-2.5 \pm 0.9^{\#}$ & $-1.6 \pm 1.4$ & $-6.0 \pm 1.3^{\#}$ & $-3.7 \pm 2.5$ & $-1.4 \pm 0.8^{*}$ \\
\hline Cortical area $(\%)$ & $-1.5 \pm 1.0$ & $-2.5 \pm 0.7^{\#}$ & $-1.0 \pm 0.9$ & $-2.7 \pm 1.0^{\#}$ & $-1.6 \pm 1.3$ & $-6.4 \pm 1.2^{\#}$ & $-1.6 \pm 1.1$ & $-1.8 \pm 0.8^{\# *}$ \\
\hline Cortical perimeter $(\%)$ & $-0.2 \pm 0.2$ & $0.0 \pm 0.1$ & $0.2 \pm 0.1$ & $-0.1 \pm 0.1$ & $-0.2 \pm 0.1^{\#}$ & $-0.3 \pm 0.2$ & $4.1 \pm 4.1$ & $-0.4 \pm 0.2$ \\
\hline Cortical porosity (\%) & $6.7 \pm 5.8$ & $-2.0 \pm 5.1$ & $13.3 \pm 8.3$ & $-1.6 \pm 5.9$ & $17.3 \pm 6.9^{\#}$ & $9.7 \pm 5.8$ & $28.6 \pm 12.5^{\#}$ & $4.3 \pm 6.6$ \\
\hline $\begin{array}{l}\text { Cortical pore diameter } \\
(\%)\end{array}$ & $1.8 \pm 2.8$ & $-2.6 \pm 2.1$ & $2.1 \pm 3.6$ & $-0.1 \pm 2.1$ & $6.2 \pm 3.1^{\#}$ & $-2.7 \pm 1.5$ & $4.6 \pm 3.2$ & $1.8 \pm 2.0$ \\
\hline $\begin{array}{l}\text { Polar moment of inertia } \\
(\%)\end{array}$ & $-1.6 \pm 1.1$ & $-2.1 \pm 0.7^{\#}$ & $-1.1 \pm 0.8$ & $-3.4 \pm 0.7^{\#}$ & $-1.7 \pm 1.1$ & $-5.0 \pm 1.3^{\#}$ & $-1.1 \pm 0.9$ & $-1.7 \pm 0.6^{\# *}$ \\
\hline Number of subjects & 21 & 19 & 18 & 19 & 23 & 20 & 20 & 20 \\
\hline \multicolumn{9}{|l|}{ Tibia } \\
\hline Total density (\%) & $-1.9 \pm 0.7^{\#}$ & $-1.9 \pm 0.6^{\#}$ & $-1.0 \pm 0.7$ & $-1.1 \pm 0.8$ & $-2.6 \pm 0.7^{\#}$ & $-3.4 \pm 0.8^{\#}$ & $-1.8 \pm 0.7^{\#}$ & $-1.5 \pm 0.9$ \\
\hline Trabecular density (\%) & $-2.0 \pm 0.9^{\#}$ & $-1.5 \pm 0.8$ & $-0.8 \pm 0.8$ & $-1.3 \pm 0.8$ & $-2.4 \pm 1.0^{\#}$ & $-2.6 \pm 0.9^{\#}$ & $-1.4 \pm 0.7$ & $-1.4 \pm 1.1$ \\
\hline $\mathrm{BV} / \mathrm{TV}(\%)$ & $-1.9 \pm 0.9^{\#}$ & $-1.5 \pm 0.8$ & $-0.9 \pm 0.8$ & $-1.2 \pm 0.8$ & $-2.4 \pm 1.0^{\#}$ & $-2.7 \pm 0.9^{\#}$ & $-1.5 \pm 0.7^{\#}$ & $-1.4 \pm 1.1$ \\
\hline Trabecular number (\%) & $1.8 \pm 1.7$ & $-1.2 \pm 2.4$ & $0.6 \pm 1.6$ & $-3.6 \pm 1.3$ & $-3.2 \pm 1.4^{\#}$ & $-2.0 \pm 2.0$ & $-1.9 \pm 1.7$ & $1.7 \pm 2.4$ \\
\hline Trabecular thickness (\%) & $-3.3 \pm 1.5^{\#}$ & $0.3 \pm 2.2$ & $-0.9 \pm 1.4$ & $2.6 \pm 1.4$ & $1.3 \pm 1.3$ & $0.0 \pm 2.1$ & $1.0 \pm 1.5$ & $-2.3 \pm 1.9$ \\
\hline $\begin{array}{l}\text { Trabecular separation } \\
(\%)\end{array}$ & $-0.9 \pm 1.8$ & $2.7 \pm 2.5$ & $-0.1 \pm 1.6$ & $4.2 \pm 1.4^{\#}$ & $4.3 \pm 1.6^{\#}$ & $3.5 \pm 2.1$ & $2.8 \pm 1.8$ & $-0.4 \pm 2.3$ \\
\hline Tb.1/N.SD (\%) & $-1.2 \pm 1.8$ & $3.7 \pm 2.5$ & $-0.4 \pm 1.3$ & $3.5 \pm 1.5^{\#}$ & $3.8 \pm 1.6^{\#}$ & $2.7 \pm 1.9$ & $2.7 \pm 1.8$ & $-1.1 \pm 2.3$ \\
\hline Trabecular area (\%) & $0.1 \pm 0.1$ & $0.2 \pm 0.1^{\#}$ & $0.0 \pm 0.1$ & $0.1 \pm 0.1$ & $0.3 \pm 0.1^{\#}$ & $0.4 \pm 0.1^{\#}$ & $0.2 \pm 0.1$ & $0.2 \pm 0.1$ \\
\hline Cortical density (\%) & $-1.7 \pm 0.4^{\#}$ & $-1.1 \pm 0.4^{\#}$ & $-1.0 \pm 0.4^{\#}$ & $-0.6 \pm 0.4$ & $-2.0 \pm 0.3^{\#}$ & $-2.3 \pm 0.5^{\#}$ & $-1.4 \pm 0.5^{\#}$ & $-1.2 \pm 0.4^{\#}$ \\
\hline Cortical thickness (\%) & $-0.7 \pm 0.6$ & $-1.5 \pm 0.7^{\#}$ & $-0.4 \pm 0.7$ & $-0.4 \pm 1.1$ & $-1.9 \pm 0.6^{\#}$ & $-3.0 \pm 1.0^{\#}$ & $-1.5 \pm 0.9$ & $-0.9 \pm 0.9$ \\
\hline Cortical area $(\%)$ & $-1.1 \pm 0.5^{\#}$ & $-1.6 \pm 0.7^{\#}$ & $-0.6 \pm 0.7$ & $-0.6 \pm 1.0$ & $-2.1 \pm 0.6^{\#}$ & $-3.1 \pm 0.9^{\#}$ & $-1.8 \pm 0.9^{\#}$ & $-1.3 \pm 0.9$ \\
\hline Cortical perimeter $(\%)$ & $-0.2 \pm 0.1^{\#}$ & $-0.1 \pm 0.1$ & $-0.2 \pm 0.1^{\#}$ & $-0.1 \pm 0.1^{\#}$ & $-0.2 \pm 0.1^{\#}$ & $-0.3 \pm 0.1^{\#}$ & $-0.2 \pm 0.1^{\#}$ & $-0.3 \pm 0.1^{\#}$ \\
\hline Cortical porosity (\%) & $6.1 \pm 3.1$ & $3.4 \pm 2.9$ & $3.3 \pm 2.9$ & $0.0 \pm 2.1$ & $9.0 \pm 3.0^{\#}$ & $8.2 \pm 3.7^{\#}$ & $14.3 \pm 5.6^{\#}$ & $2.9 \pm 2.7$ \\
\hline $\begin{array}{l}\text { Cortical pore diameter } \\
(\%)\end{array}$ & $-0.7 \pm 1.8$ & $2.4 \pm 2.3$ & $-2.6 \pm 1.6$ & $3.5 \pm 0.8^{\#}$ & $3.2 \pm 1.3^{\#}$ & $1.9 \pm 2.2$ & $1.2 \pm 2.0$ & $1.3 \pm 1.5$ \\
\hline $\begin{array}{l}\text { Polar moment of inertia } \\
(\%)\end{array}$ & $-0.2 \pm 0.4$ & $-2.1 \pm 1.0^{\#}$ & $-0.9 \pm 0.6$ & $-1.9 \pm 1.0$ & $-2.0 \pm 0.4^{\#}$ & $-3.9 \pm 1.1^{\#}$ & $-1.6 \pm 0.8$ & $-1.7 \pm 0.9$ \\
\hline
\end{tabular}

The values are given as the mean \pm SEM. With a two-way ANOVA, there was no statistically significant between-group difference nor interaction $\# p<0.05$ vs baseline; ${ }^{*} p<0.05$ between groups, using a $t$ test

phenotype, combining higher bone formation, independent of resorption, and high bone mass [26].
Accordingly, calcitonin would be expected to decrease bone formation. In rat osteocytes, calcitonin has been 

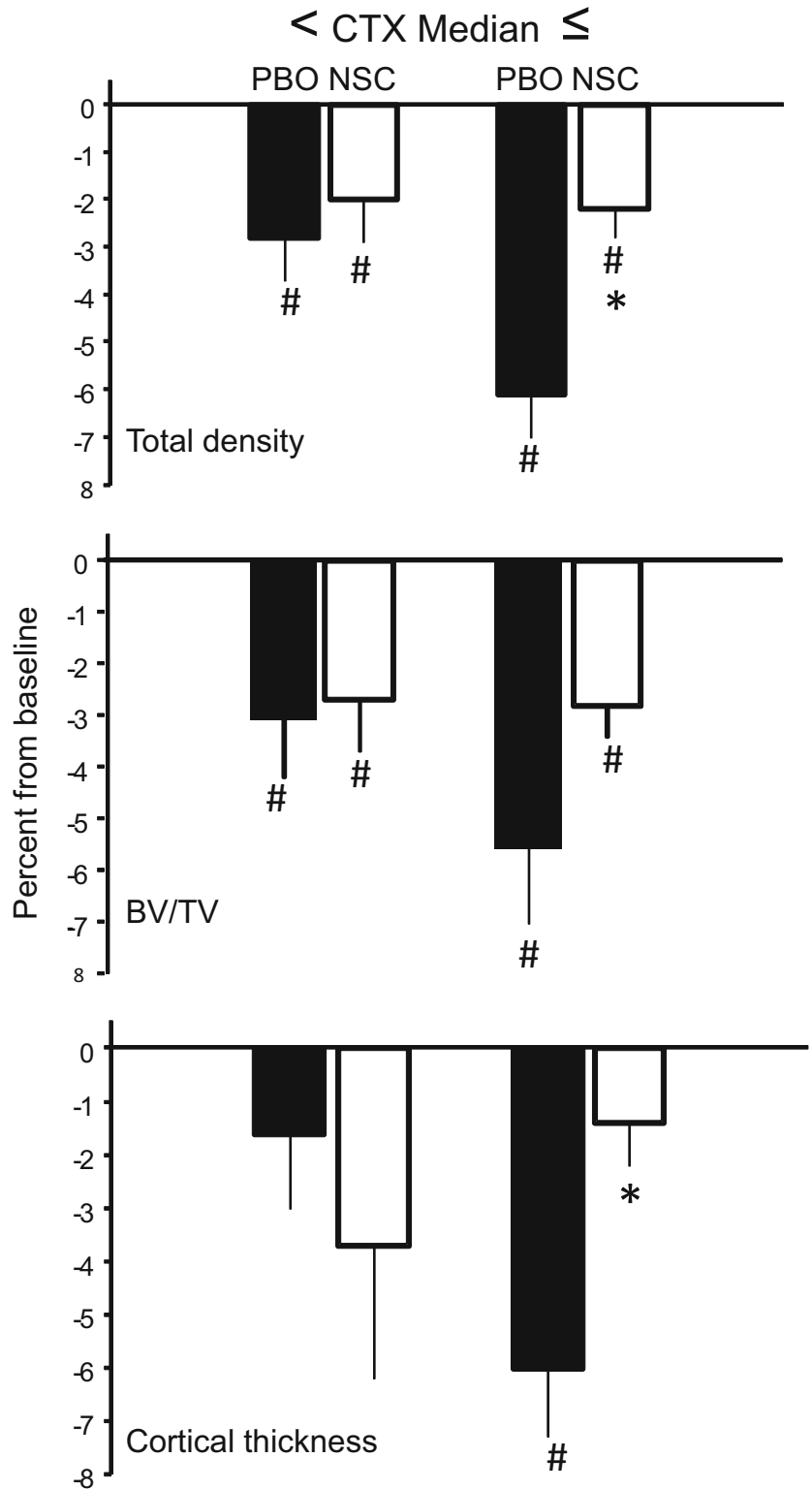

Fig. 3 Effects of nasal salmon calcitonin (NSC) on distal radius total density, relative bone volume (BV/TV), and cortical thickness at 2 years, in relation to baseline CTX levels. Values are percent changes from baseline. Dark columns, placebo; open columns, NSC. $\# p<0.05$ vs baseline. ${ }^{*} p<0.05$ between-group difference using a $t$ test

shown to upregulate sclerostin expression [16], suggesting that calcitonin may thereby inhibit bone formation through this factor. Without knowing whether circulating sclerostin is a reliable reflection of this cytokinemediated reduction in bone production [20] and whether the rodent findings can be confirmed in humans, we measured plasma sclerostin [20] and only found a blunted decrease over time at 18 months on NSC. There was no difference in sclerostin levels between
NSC and placebo groups at time points at which the effects of NSC on bone resorption markers were detectable.

NSC was well tolerated, with a lower incidence of arthralgia in the treated group than the placebo, reflecting the fact that calcitonin and CGRP receptors are present in the central nervous system, and likely mediate an analgesic effect [27, 28]. A meta-analysis of 17 randomized control trials with NSC has suggested a slight increase in the risk of cancer in patients on long-term calcitonin therapy [29]. These findings were not confirmed in a more recent and thorough metaanalysis [30]. No specific tumor type, patient profile, dose-dependency, nor any causal mechanisms have been identified. In the present study, we recorded two cases of malignancy: one in the NSC-treated group and one in the placebo group.

The strengths of our study are that it was conducted in a single center, thereby reducing the inter-center and inter-instrument variability; it was performed in a population of healthy non-osteoporotic postmenopausal women, decreasing thus the influence of age-related confounding factors; this class of age, relatively close to menopause, and being thus associated with higher bone turnover, constitutes a population in whom it might be more likely to detect a response to calcitonin [23]. The limitations of the study are the number of subjects recruited, precluding small differences from reaching a level of statistical significance, and possibly an inadequate long-term compliance despite repeated information dissemination and verification by medication return counting. However, the number of subjects enrolled was similar to the QUEST study in which bone microstructure was evaluated using MRI and found to be modified in patients with prevalent vertebral fractures [15].

In conclusion, our results confirm a mild inhibition of bone turnover by NSC. This was associated with a blunting of microstructural alterations at the distal radius and distal tibia, particularly in subjects with higher bone turnover. NSC-dependent bone microstructure protection may contribute to the lower fracture risk previously reported in one study [12]. Further investigations in larger cohorts are required to confirm these findings.

Acknowledgments This study was supported by a grant from Novartis AG, Switzerland. We thank Mr G. Conicella for BMD and bone microstructure measurements, Dr Pierre Lescuyer PhD for some biochemical determinations, and Ms Katy Giroux for secretarial assistance.

Conflicts of interest RR has received consulting fees/lecture fees from Amgen, MSD, GSK, Servier, Danone, Takeda. MA was an employee of Novartis. AS and FRH have nothing to disclose. 


\section{References}

1. Kanis JA, Burlet N, Cooper C, Delmas PD, Reginster JY, Borgstrom F, Rizzoli R (2008) European guidance for the diagnosis and management of osteoporosis in postmenopausal women. Osteoporos Int 19:399-428

2. Ammann P, Rizzoli R (2003) Bone strength and its determinants. Osteoporos Int 14(Suppl 3):S13-18

3. Boutroy S, Bouxsein ML, Munoz F, Delmas PD (2005) In vivo assessment of trabecular bone microarchitecture by high-resolution peripheral quantitative computed tomography. J Clin Endocrinol Metabol 90:6508-6515

4. Chevalley T, Bonjour JP, Ferrari S, Rizzoli R (2009) Deleterious effect of late menarche on distal tibia microstructure in healthy 20year-old and premenopausal middle-aged women. J Bone Mineral Res Off J Am Soc Bone Mineral Res 24:144-152

5. Rizzoli R (2011) Bisphosphonates for post-menopausal osteoporosis: are they all the same? QJM: Monthly J Assoc Phys 104:281-300

6. Murad MH, Drake MT, Mullan RJ et al (2012) Clinical review. Comparative effectiveness of drug treatments to prevent fragility fractures: a systematic review and network meta-analysis. J Clin Endocrinol Metab 97:1871-1880

7. Kanis JA, McCloskey EV, Johansson H, Cooper C, Rizzoli R, Reginster JY (2013) European guidance for the diagnosis and management of osteoporosis in postmenopausal women. Osteoporos Int 24:23-57

8. Davey RA, Findlay DM (2013) Calcitonin: physiology or fantasy? J Bone Min Res 28:973-979

9. Chesnut CH 3rd, Azria M, Silverman S, Engelhardt M, Olson M, Mindeholm L (2008) Salmon calcitonin: a review of current and future therapeutic indications. Osteoporos Int 19: 479-491

10. Kanis JA, McCloskey EV (1999) Effect of calcitonin on vertebral and other fractures. QJM: Monthly J Assoc Physicians 92:143-149

11. Overgaard K, Hansen MA, Jensen SB, Christiansen C (1992) Effect of salcatonin given intranasally on bone mass and fracture rates in established osteoporosis: a dose-response study. BMJ 305:556-561

12. Chesnut $\mathrm{CH}$ 3rd, Silverman S, Andriano K et al (2000) A randomized trial of nasal spray salmon calcitonin in postmenopausal women with established osteoporosis: the prevent recurrence of osteoporotic fractures study. PROOF Study Group. Am J Med 109:267-276

13. Gennari C, Agnusdei D, Montagnani M, Gonnelli S, Civitelli R (1992) An effective regimen of intranasal salmon calcitonin in early postmenopausal bone loss. Calcif Tissue Int 50:381-383

14. Thamsborg G, Jensen JE, Kollerup G, Hauge EM, Melsen F, Sorensen OH (1996) Effect of nasal salmon calcitonin on bone remodeling and bone mass in postmenopausal osteoporosis. Bone $18: 207-212$

15. Chesnut CH 3rd, Majumdar S, Newitt DC et al (2005) Effects of salmon calcitonin on trabecular microarchitecture as determined by magnetic resonance imaging: results from the QUEST study. J Bone Min Res 20:1548-1561
16. Gooi JH, Pompolo S, Karsdal MA et al (2010) Calcitonin impairs the anabolic effect of PTH in young rats and stimulates expression of sclerostin by osteocytes. Bone 46:1486-1497

17. Richert L, Uebelhart B, Engelhardt M, Azria M, Rizzoli R (2008) A randomized double-blind placebo-controlled trial to investigate the effects of nasal calcitonin on bone microarchitecture measured by high-resolution peripheral quantitative computerized tomography in postmenopausal women - study protocol. Trials 9:19

18. Genant HK, Jergas M (2003) Assessment of prevalent and incident vertebral fractures in osteoporosis research. Osteoporos Int 14(Suppl 3): S43-55

19. Burghardt AJ, Buie HR, Laib A, Majumdar S, Boyd SK (2010) Reproducibility of direct quantitative measures of cortical bone microarchitecture of the distal radius and tibia by HR-pQCT. Bone 47:519-528

20. Durosier C, Van Lierop A, Ferrari S, Chevalley T, Papapoulos S, Rizzoli R (2013) Association of circulating sclerostin with bone mineral mass, microstructure, and turnover biochemical markers in healthy elderly men and women. J Clin Metab 98(9): 3873-3883

21. Buchs B, Rizzoli R, Bonjour JP (1991) Evaluation of bone resorption and renal tubular reabsorption of calcium and phosphate in malignant and nonmalignant hypercalcemia. Bone 12:47-56

22. Rizzoli R, Boonen S, Brandi ML, Bruyere O, Cooper C, Kanis JA, Kaufman JM, Ringe JD, Weryha G, Reginster JY (2013) Vitamin D supplementation in elderly or postmenopausal women: a 2013 update of the 2008 recommendations from the European Society for Clinical and Economic Aspects of Osteoporosis and Osteoarthritis (ESCEO). Curr Med Res Opin 29:305-313

23. Civitelli R, Gonnelli S, Zacchei F, Bigazzi S, Vattimo A, Avioli LV, Gennari C (1988) Bone turnover in postmenopausal osteoporosis. Effect of calcitonin treatment. J Clin Investig 82:1268-1274

24. Copp DH, Cheney B (1962) Calcitonin - a hormone from the parathyroid which lowers the calcium-level of the blood. Nature 193: 381-382

25. Binkley N, Bolognese M, Sidorowicz-Bialynicka A, Vally T, Trout R, Miller C, Buben CE, Gilligan JP, Krause DS (2012) A phase 3 trial of the efficacy and safety of oral recombinant calcitonin: the Oral Calcitonin in Postmenopausal Osteoporosis (ORACAL) trial. J Bone Min Res 27:1821-1829

26. Hoff AO, Catala-Lehnen P, Thomas PM et al (2002) Increased bone mass is an unexpected phenotype associated with deletion of the calcitonin gene. J Clin Invest 110:1849-1857

27. Silverman SL, Azria M (2002) The analgesic role of calcitonin following osteoporotic fracture. Osteoporos Int 13:858-867

28. Gennari C (2002) Analgesic effect of calcitonin in osteoporosis. Bone 30:67S-70S

29. Heep M LS, Gasser J, Aftring P (2002) Calcitonin use and risk of malignancy: a meta-analysis of 17 RCTs in patients with osteoporosis. J Bone Miner Res 27 (Suppl 1) Available at http://www. asbmrorg/Meetings/AnnualMeeting/AbstractDetailaspx?aid= 7edc522d-7ab7-492b-acaa-25ba919ca7d2

30. Wells G, Krause D, Chernoff J, Gilligan J Does calcitonin cause cancer? J Bone Miner Res 28 (Suppl 1) Available at http://www. asbmr.org/education/AbstractDetail?aid=d04e9f37-0e18-43ab-9cbfe64e19ba8d5a 